\title{
Effect of a new synthetic ascorbic acid derivative as a free radical scavenger on the development of acute pancreatitis in mice
}

\author{
A Nonaka, T Manabe, $\mathrm{T}$ Tobe
}

\begin{abstract}
The therapeutic effects of CV 3611, a new synthetic free radical scavenger prepared from an ascorbic acid derivative, on choline deficient, ethionine enriched (CDE) diet induced acute pancreatitis in mice were evaluated and compared with those of superoxide dismutase. Time/course studies after subcutaneous injection of CV 3611 in normal mice showed a peak plasma concentration of mean (SEM) 0.54 (0.09) $\mu \mathrm{g} / \mathrm{ml}$ at one hour, with a gradual decrease over the next 10 hours, while a peak concentration in pancreatic tissue of mean (SEM) 425 (33) $\mathrm{ng} / \mathrm{g}$ tissue was achieved at three hours and the drug was undetectable at 12 hours. Survival rates and activities of pancreatic enzymes (amylase, lipase, elastase I) were compared in control mice and animals that received CV 3611 before or at the time of feeding the CDE diet. The survival rate was observed in a no treatment group and mice given pretreatment or treatment with CV 3611 or superoxide dismutase. The survival rate was significantly better in the treatment group given CV $3611(p<0.02)$, but superoxide dismutase had no significant effect on survival. The increases in the three serum enzyme activities were significantly less at $\mathbf{4 8}$ hours in the groups given pretreatment or treatment with CV 3611 than in the no treatment group. These results indicate that CV 3611, which has been proved to pass through the cell membrane and to have a long half life in plasma and tissue, had an important therapeutic effect on the development of acute pancreatitis. They also suggest that oxygen derived free radicals may play an important role in the development of acute pancreatitis.
\end{abstract}

The role of oxygen derived free radicals in the pathogenesis of acute pancreatitis has been reported recently. ${ }^{12}$ In the sequential univalent process of the complete reduction of molecular oxygen to water, several oxygen intermediates for example, superoxide anion $\left(\mathrm{O}_{2}^{-}\right)$, hydrogen peroxide $\left(\mathrm{H}_{2} \mathrm{O}_{2}\right)$, and the hydroxyl radical $(\mathrm{OH} \cdot)$ - are encountered in a living system. ${ }^{3}$ Normally, only small amounts of these toxic intermediates are produced and they are detoxified by endogenous free radical scavengers such as superoxide dismutase and catalase and antioxidant substances such as $\alpha$ tocopherol and ascorbic acid. In disease, however, the production of active oxygen species may be increased and the working of the scavenging system may be decreased.' This being the case, exogenous free radical scavengers might be expected to protect against damage to organs caused by the overproduction of oxygen radicals in disease. Sanfey $e t a l^{1}$ and Guice $e t a l^{2}$ attempted to use exogenous scavengers such as superoxide dismutase, catalase, and dimethylsulfoxide in experimental pancreatitis to clarify the role of oxygen derived free radicals. Controversy exists, however, on their effects. ${ }^{2}$ The molecular weights of superoxide dismutase and catalase are too great to enable the molecules to pass through the biomembrane. Furthermore, the circulation half life of exogenous superoxide dismutase is too short and it rapidly leaves the tissues via the blood stream. Rutledge $e t a l^{6}$ reported that exogenous scavengers and inhibitors - for example catalase, dimethylsulfoxide, and allopurinol - have little or no therapeutic effects on acute pancreatitis induced by a choline deficient, ethionine enriched (CDE) diet. A new synthetic scavenger made from an ascorbic acid derivative, 2-0-octadecylascorbic acid $\left(\mathrm{C}_{24} \mathrm{H}_{44} \mathrm{O}_{6}\right)$, molecular weight $428 \cdot 6$, has a strong scavenging or antioxidant effect, or both, on superoxide production by polymorphonuclear leucocytes and on the reduction of the chemically stable radical diphenylpicrylhydrazyl as shown by electron spin resonance spectroscopy. ${ }^{78}$ Recently, Kuzuya et al ${ }^{9}$ observed in vivo that this synthetic scavenger CV 3611 was effective in canine myocardial reperfusion injury. The molecular weight of CV 3611 (428.6) is much less than that of superoxide dismutase $(30000-80000)$ or catalase (24000). Because of this CV 3611 can pass through the biomembrane of the cell. In addition, the half life of CV 3611 in plasma is much greater, which means that it is also retained for longer in the tissues.

We aimed to determine whether CV 3611, which has overcome some of the disadvantages of free superoxide dismutase in terms of circulation half life and fixation or penetration, or both, to the cells, has a therapeutic effect on the development of severe acute pancreatitis and to clarify the role of oxygen derived free radicals in CDE diet induced pancreatitis.

\section{Methods}

Female BALB/c mice, each weighing 12-16 g and obtained from the Shizuoka Experimental Animal Center in Japan were used in all of the experiments. Acute pancreatitis was induced by a CDE diet as described by Lombardi et al. ${ }^{10}$ $\mathrm{Cu}, \mathrm{Zn}$ superoxide dismutase, which is synthesised biotechnologically, was obtained from Nihon Kayaku Corporation, Tokyo, Japan. The ascorbic acid derivative, CV 3611 was obtained from Takeda Chemical Industries, Osaka, Japan. Gum arabic, $99 \%$ ethanol, DL ethionine 
and other reagents were purchased from Nakarai Chemical Corporation, Kyoto, Japan.

\section{EXPERIMENTAL PROCEDURE}

\section{Survival rate}

The experimental mice were divided into three control groups, a no treatment group, two pretreatment groups, and two treatment groups. After an overnight fast, the control groups were given a normal diet with intraperitoneal superoxide dismutase $(10 \mathrm{mg} / \mathrm{kg})(\mathrm{n}=10), 1 \%$ gum arabic subcutaneously $(n=10)$, or $1 \%$ gum arabic plus subcutaneous CV $3611(10 \mathrm{mg} / \mathrm{kg})(\mathrm{n}=10)$. The no treatment group $(n=27)$ were given a CDE diet with subcutaneous gum arabic and intraperitoneal saline. The pretreatment groups were given intraperitoneal superoxide dismutase (10 $\mathrm{mg} / \mathrm{kg})(\mathrm{n}=10)$ or subcutaneous $1 \%$ gum arabic plus CV $3611(10 \mathrm{mg} / \mathrm{kg})(\mathrm{n}=15) 12$ hours before the CDE diet. The treatment groups were given intraperitoneal superoxide dismutase (10 $\mathrm{mg} / \mathrm{kg})(\mathrm{n}=15)$ or subcutaneous $1 \%$ gum arabic plus CV $3611(10 \mathrm{mg} / \mathrm{kg}) 12$ hours after the $\mathrm{CDE}$ diet. And the survival rates from 0 to 4 days were observed in each group.

\section{Concentration of CV 3611 in plasma and pancreatic tissue}

Forty eight normal mice were divided into two groups of 28 and 20 respectively. After an overnight fast a normal diet was given to each group for 12 hours. In the first group, blood sampling by cardiac puncture $(n=4$ at each time period) was performed at $0,1,2,4,6,10$, and 24 hours after subcutaneous administration of CV $3611(10 \mathrm{mg} / \mathrm{kg})$ to measure the concentration of CV 3611 in the plasma. The second group were killed by a blow to the neck, and the pancreas ( $n=4$ at each time period) was removed $0,3,6,12$, and 24 hours after subcutaneous administration of CV $3611(10 \mathrm{mg} / \mathrm{kg})$ to measure its concentration in pancreatic tissue.

\section{Assay for amylase, lipase, and elastase I}

One hundred and ten normal mice were divided into three groups of 40,40 , and 30 respectively. After an overnight fast a CDE diet was given to each group for 12 hours. Blood sampling by cardiac puncture was performed at $0,12,24,36$, and 48 hours after the CDE diet had been taken and pancreatic enzyme activities (amylase, lipase $(n=8)$, elastase $I(n=6))$ activities were measured in blood from CV 3611 treated groups.

\section{ASSAYS}

Concentration of CV 3611 in plasma and pancreatic tissues

The concentration of $\mathrm{CV} 3611$ in blood was determined. Blood samples $(0.5 \mathrm{ml})$ were deproteinised with ethanol $(4.5 \mathrm{ml})$, and centrifuged at $3000 \mathrm{rpm}$ for 10 minutes. The supernatant $(4 \mathrm{ml})$ was concentrated in a vacuum, and the concentrate was diluted with methanol $(0.15 \mathrm{ml})$ and water $(0.05 \mathrm{ml})$. The suspension was stirred for
30 seconds then centrifuged at $3000 \mathrm{rpm}$ for 10 minutes. The aliquot $(0.1 \mathrm{ml})$ was analysed by reversed phase high performance liquid chromatography (HPLC, Hitachi 655A-11). The reversed phase HPLC system consisted of a $\mathrm{C} 18$ Inertsil ODS $5 \mu \mathrm{m}$ column $(4.5 \times 150 \mathrm{~mm})$ with a mobile phase of $\mathrm{CH}_{3} \mathrm{CN} /$ methanol/water/acetic acid (1000:250:150:1). The flow rate was $1.5 \mathrm{ml} / \mathrm{minute}$ and $\mathrm{CV} 3611$ was detected by ultraviolet spectroscopy (Hitachi 655A) at $240 \mathrm{~nm}$. The amounts of CV 3611 were calculated by the use of external standards.

All procedures to determine the content of CV 3611 were done at room temperature unless otherwise noted. Pancreatic tissue samples (130 mg) were homogenised with $2.9 \mathrm{ml}$ of ethanol and $0.1 \mathrm{ml}$ of $50 \%$ ethanol tissues containing $0 \cdot 1 \%$ ascorbic acid. The homogenate was centrifuged at $3000 \mathrm{rpm}$ for five minutes. Some $1 \mathrm{ml}$ of $0 \cdot 1 \mathrm{M}$ phosphate buffer ( $\mathrm{pH} \mathrm{5 \cdot 0)}$ was added to the supernatant $(3 \mathrm{ml})$ which was then washed twice by shaking with $4 \mathrm{ml}$ of $\mathrm{n}$-hexane for five minutes. After centrifugation at $3000 \mathrm{rpm}$ for five minutes, the $3 \mathrm{ml}$ of the lower layer was evaporated to dryness in a vacuum at $40^{\circ} \mathrm{C}$. The concentrate was diluted with $0.5 \mathrm{ml}$ of a mobile phase of $\mathrm{CH}_{3} \mathrm{CN} /$ ethanol/ $0.05 \mathrm{M} \mathrm{NH} \mathrm{NH}_{2} \mathrm{PO}_{4}$ (pH 4.0) (36:36:28), sonicated with a sonicator (Branson B-220-J), then filtered through a membrane filter (Milipore filter; $\varnothing=0.45 \mu \mathrm{m})$. The aliquot $(0.1 \mathrm{ml})$ was analysed by reversed phase HPLC (Hitachi L 6200 ) consisting of a TSK gel ODS-80TM $(4 \cdot 6 \times 150 \mathrm{~mm})$ column, temperature $50^{\circ} \mathrm{C}$, with a mobile phase of $\mathrm{CH}_{3} \mathrm{CN} / \mathrm{methanol} /$ water/acetic acid (1000:250:150:1). The flow rate was $1 \mathrm{ml} /$ minute and the absorbance change at
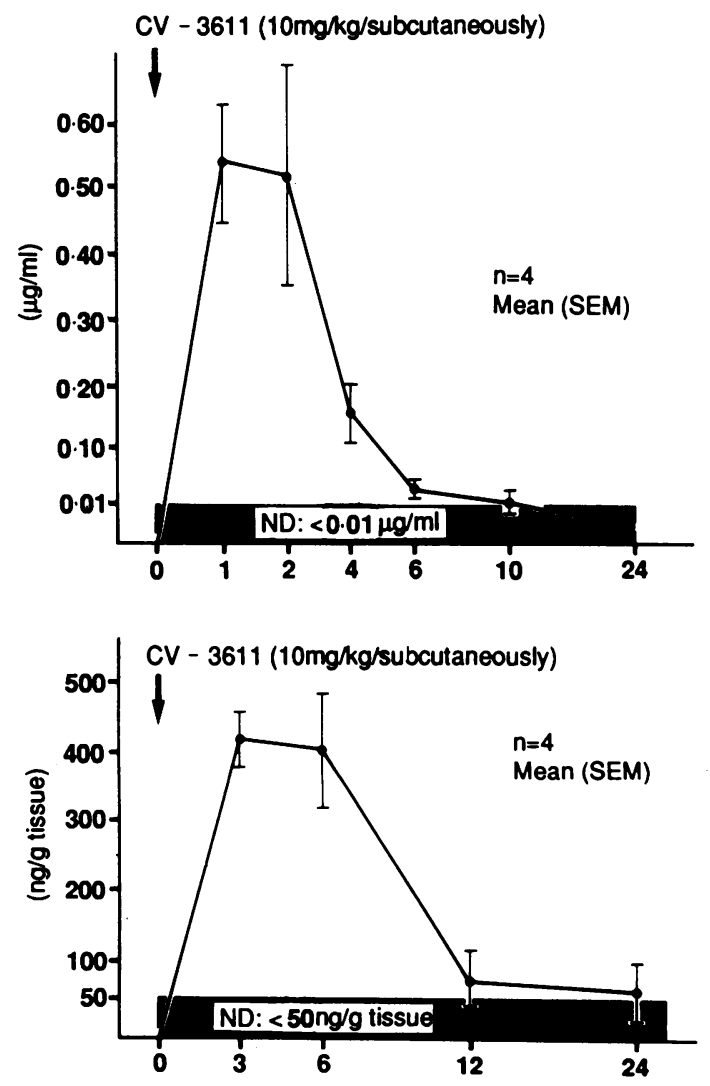

Figure 1: Changes in CV 3611 concentrations in plasma (top) and pancreatic tissue (bottom) in mice. 
Figure 2: Effect of superoxide dismutase (SOD) on the survival rate in choline deficient, ethionine enriched $(C D E)$ diet induced acute pancreatitis in mice.

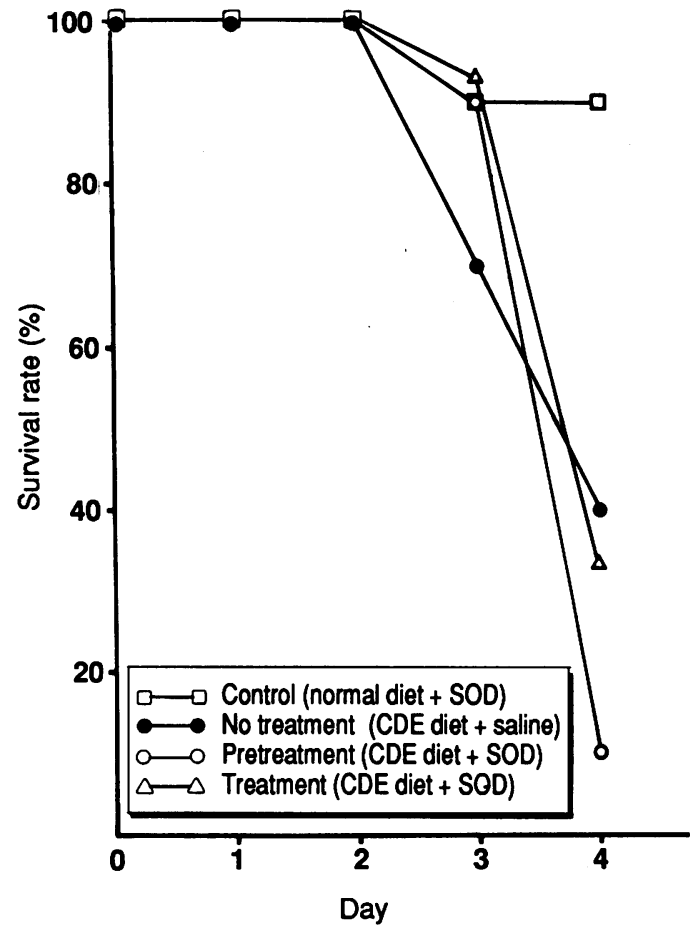

$262 \mathrm{~nm}$ (Hitachi L 4000) was used to determine the CV 3611 concentration by the absolute calibration curve method.

Assay for amylase, lipase, and elastase I

Serum amylase and lipase were measured using the methods of Teshima $e t a l^{11}$ and Kurooka $e t$ $a l^{12}$ respectively. Serum elastase I was measured by the method of Murata et al. ${ }^{13}$ Pancreatic elastase I was purified from pancreatic juice in an active form. Antiserum was raised in rabbits by repeated subcutaneous injections of $1 \mathrm{mg}$ of purified enzyme. The antiserum obtained was used at a dilution of $1: 10^{4}$, which gave approximately $40 \%$ of the maximal binding of the labelled antigen. The antibody may cross react with proelastase, however, pancreatic pro-

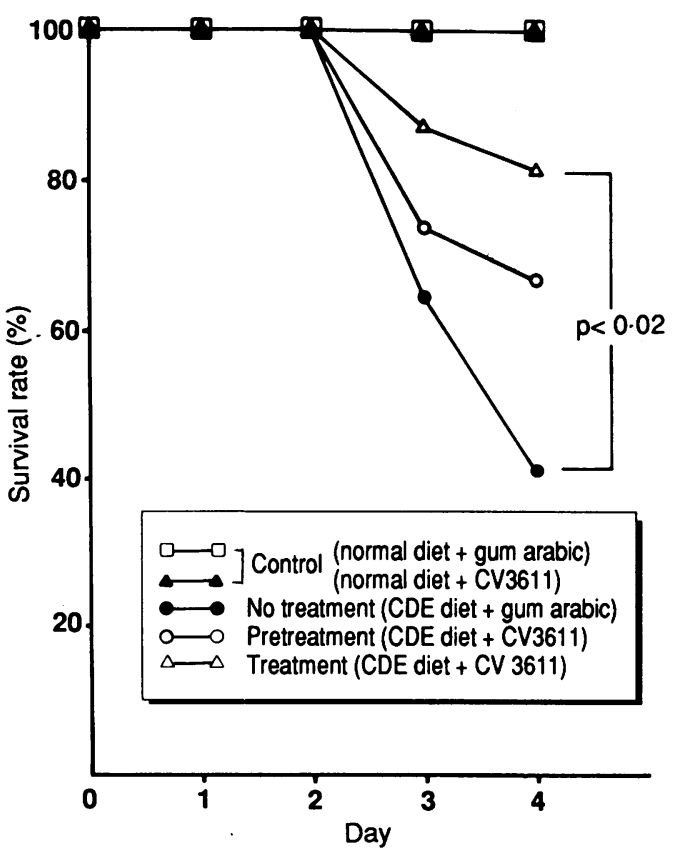

elastase enters the blood stream and is then rapidly activated. The activity of elastase $I$ in this study showed that it was almost all immunoreactive elastase $\mathrm{I}$.

\section{STATISTICAL ANALYSIS}

The results reported in this study represent the mean (SEM). Differences between groups were evaluated using the Student's $t$ test. A probability of less than 0.05 is statistically significant. The survival rate was analysed using the $\chi^{2}$ method with Yates's correction. ${ }^{14}$

\section{Results}

CHANGES IN CV 36I I CONCENTRATIONS IN PLASMA AND PANCREAS AFTER SUBCUTANEOUS

ADMINISTRATION (IO MG/KG) (FIG I)

The concentration of CV 3611 in plasma reached a peak mean (SEM) value of $0.54(0.09) \mu \mathrm{g} / \mathrm{ml}$ at one hour then gradually decreased until it was almost undetectable 24 hours after administration (CV 3611 is undetectable at concentrations of less than $0.01 \mu \mathrm{g} / \mathrm{ml}$ ). The CV 3611 concentration of pancreatic tissue reached a peak mean (SEM) of 425 (37) ng/g tissue at three hours and almost disappeared 24 hours after administration (CV 3611 becomes undetectable at concentrations less than $50 \mathrm{ng} / \mathrm{g}$ tissue).

EFFECT OF CV 36I I AND SUPEROXIDE DISMUTASE ON SURVIVAL RATE IN CDE DIET INDUCED ACUTE PANCREATITIS (FIGS 2 AND 3)

In the mice given intraperitoneal superoxide dismutase $(10 \mathrm{mg} / \mathrm{kg})$, no significant differences between the group given CDE diet only and those given pretreatment or treatment with superoxide dismutase were observed at any time during the experiment. The normal diet plus superoxide dismutase group had a $90 \%$ four day survival rate. However, the group given subcutaneous CV 3611 (10 mg/kg) showed a significantly improved survival rate over the CDE diet only group. The four day survival rates were $81.3 \%$ in the treatment group $(\mathrm{p}<0.02), 66.7 \%$ in the pretreatment group, and $41.2 \%$ in the no treatment group after the feeding of the CDE diet. The $1 \%$ gum arabic or $1 \%$ gum arabic plus CV $3611(10 \mathrm{mg} / \mathrm{kg})$ with normal diet groups showed four day survival rates of $100 \%$.

CHANGES IN SERUM AMYLASE, LIPASE, AND ELASTASE I ACTIVITIES IN NO TREATMENT, PRETREATMENT, AND TREATMENT GROUPS AFTER CDE DIET (FIGS 4 AND 5)

The effect of CV 3611 on serum amylase and lipase activities $(n=8)$ was determined. In the no treatment group, the serum amylase activity increased appreciably from a basal level of mean (SEM) 2088 (146) somogi units (SU) to 14830 (1240) SU 48 hours after the CDE diet $(p<0.01)$. In the pretreatment and treatment groups, the amylase activities at 48 hours were lower - mean (SEM) 6320 (680) SU (p<0.01) and 4000 (500) SU $(p<0.01)$, respectively - than that of the no treatment group. In the no treatment group, the
Figure 3: Effect of CV 3611 on the survival rate in choline defient, ethionine enriched pancreatitis in mice.

There was a significan increase in the survival rate of the group treated with $C V$ 3611 compared with the no treatment group. 
Figure 4: Effect of CV 3611 on the serum amylase and lipase activities in mice given a choline deficient, ethionine

A significant reduction in serum amylase and lipase values 48 hours after the administration of CV 3611 was observed for the pretreatment and treatment groups compared with the no treatment group. enriched (CDE) diet.
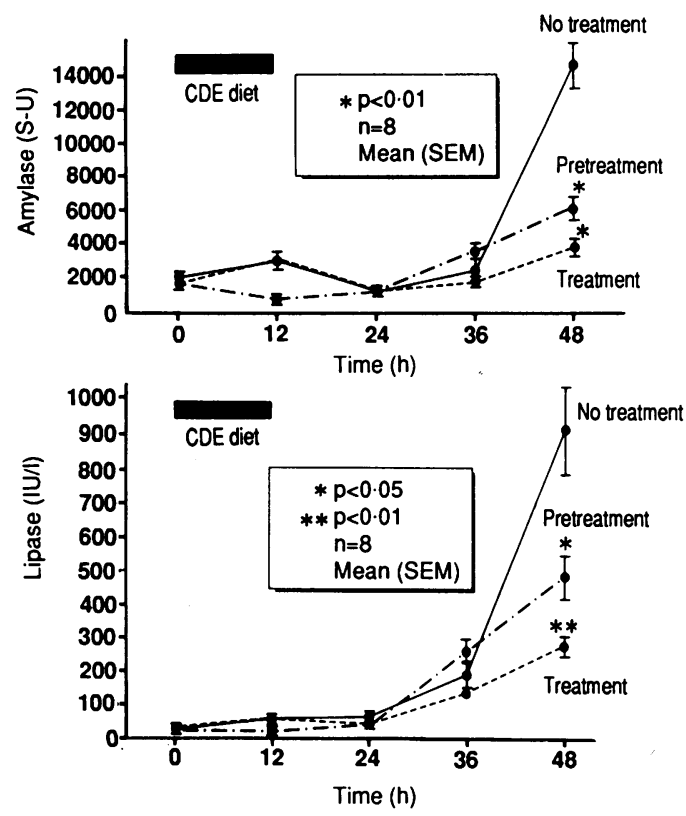

serum lipase activity also increased considerably from a basal value of mean (SEM) 34 (5) IU/l to 920 (110) IU/1 48 hours after the CDE diet $(\mathrm{p}<0.001)$. In the pretreatment and treatment groups, the serum lipase activities at 48 hours were lower - mean (SEM) $473(67)$ IU/l $(p<0.05)$ and $280(30) \mathrm{IU} / 1(\mathrm{p}<0.01)$, respectively - than that of the no treatment group.

The effect of CV 3611 on the serum elastase I activity $(n=6)$ was determined. In the no treatment group, the serum elastase I value increased considerably from a basal activity of mean (SEM) $160(10) \mathrm{ng} / \mathrm{dl}$ to $510(85) \mathrm{ng} / \mathrm{dl} 48$ hours after the $\mathrm{CDE}$ diet $(\mathrm{p}<0.001)$. In the pretreatment and treatment groups, the serum elastase I activities were mean $($ SEM) $250(35) \mathrm{ng} / \mathrm{dl}(\mathrm{p}<0.05)$ and $260(20) \mathrm{ng} / \mathrm{dl}(\mathrm{p}<0.01)$ respectively at 48 hours. Therefore, the increases in serum elastase $I$ values at 48 hours were also reduced significantly, compared with the value in the no treatment group (both $\mathrm{p}<0 \cdot 05$ ).

\section{Discussion}

Oxygen derived free radicals have recently been reported to play an important role in the pathogenesis of many disorders of the living system. ${ }^{15}{ }^{16}{ }^{17}$ Braganza $^{18}$ proposed that oxidative stress initiates acute pancreatitis by interfering with the regulated secretory pathway in pancreatic acinar cells and that treatment with antioxidants, by overcoming the metabolic blockade, may assist in management. Very recent observations incriminate free radicals as the common trigger in acute pancreatitis and

Figure 5: Effect of CV 3611 on the serum elastase I values in mice fed a choline deficient, ethionine enriched $(C D E)$ diet.

A significant reduction in elastase I values at 48 hour was observed for the pretreatment and treatment groups compared with the no treatment group.

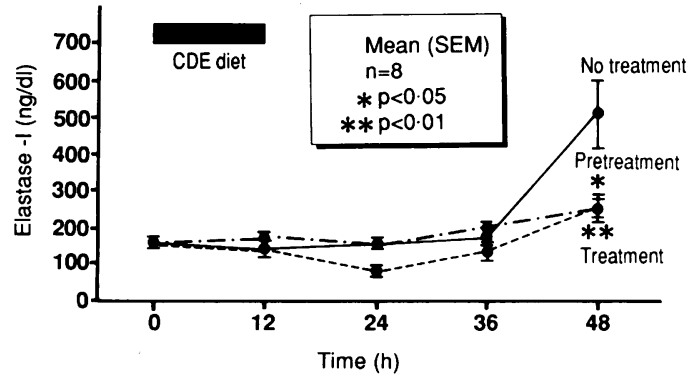

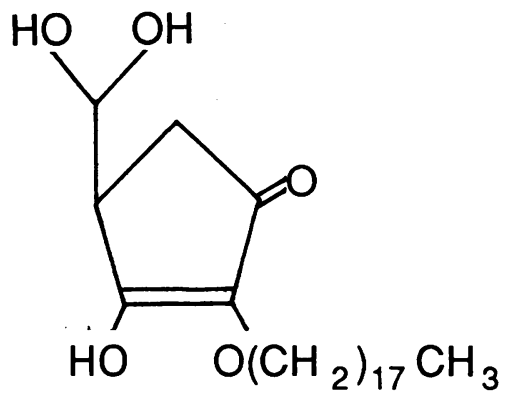

Figure 6: The structure of CV 3611.

suggest that these, along with elastase, phospholipase $A_{2}$, and other substances that are discharged into the pancreatic interstitium by activated leucocytes, ${ }^{19} 20$ may effect the transformation to interlobular/periglandular fat necrosis, haemorrhage, and coagulative necrosis. Rinderknecht ${ }^{21}$ hypothesised that the complex pathological processes responsible for the high mortality in severe acute pancreatitis can largely be explained as resulting from excessive stimulation of leucocytes which leads to the liberation of oxygen radicals and biological reference modifiers.

We have attempted to clarify the role of oxygen radicals in the pathogenesis of acute pancreatitis in mice. We have shown in this study that CV 3611, a potent free radical scavenger that has overcome some of the detrimental properties of free superoxide dismutase, effectively reduced extravasation of pancreatic enzymes and increased survival rate in CDE diet induced pancreatitis. The evidence suggests that antioxidants may help in reversing secretory polarity, but not perhaps after frustrated phagocytosis has set in. These data, while hinting at the importance of normal exocytosis in preserving pancreatic integrity, underline the importance of considering the biophysical properties of potential antioxidants for the treatment of experimental and human pancreatitis.

The scavenging effect of CV 3611 is shown in both the model of the polymorphonuclear leucocyte $\mathrm{O}_{2}^{-}$producing system and the inhibition of lipid peroxidation of linoleic acid caused by $\mathrm{O}_{2}{ }^{-}$, $\mathrm{OH}$, and $\mathrm{LOOH} .{ }^{78} \mathrm{CV} 3611$ is a novel scavenger that scavenges several free radicals including $\mathrm{O}_{2}{ }^{-}, \mathrm{OH} \cdot$, LOO $\cdot$, LO $\cdot$, and $\mathrm{L} \cdot \mathrm{CV} 3611$, which has a high affinity for the biomembrane, is introduced by lipophilic groups on the hydroxyls of the 2- or 3-carbon in ascorbic acid, and may exert a scavenging activity not only by maintaining an interaction with membrane phospholipids but also by suppressing superoxide production of the membrane associated superoxide generating system.

Kuzuya et al showed that CV 3611 exhibited a dose dependent inhibition of free radical generation and that in vivo administration was also effective on myocardial reperfusion injury in dogs.

The molecular weight of CV 3611 is very small $(428 \cdot 6)$. Its structure is shown in Figure 6.

Penetration of the biomembrane was confirmed in an experiment by using radioactive carbon labelled CV 3611. The amounts of ${ }^{14} \mathrm{C}$ labelled CV 3611 in the subcellular fraction six hours after administration were $100 \%$ in the 
homogenate, $18 \cdot 7 \%$ in the nucleus, $13 \cdot 1 \%$ in the mitochondria, $22 \cdot 1 \%$ in the microsome, and $58.4 \%$ in the cytosol (unpublished data). In this study, we also clarified the long circulation half life and the fixation of CV 3611 to the pancreatic tissue in mice.

Wisner et $a l^{22}$ reported that it is not clear whether the protective effects of exogenous polyethylene glycol-superoxide dismutase on caerulein induced pancreatitis are due to the enzyme's intracellular or extracellular action on the pancreas. They also suggested that exogenous polyethylene glycol-superoxide dismutase could be acting extracellularly through catalytic inactivation of superoxide anion diffusing into the interstitium from acinar cells, since compounds such as $\mathrm{O}_{2}^{-}$and $\mathrm{H}_{2} \mathrm{O}_{2}$ can pass through cell membranes by either diffusion or transport through anionic membrane channels. However, when superoxide generated in the cell by systems such as the electron transport system in the inner membrane of mitochondria, nicotinamide-adenine-dinucleotide phosphate oxidase system, cytochrome $\mathrm{P} 450$ reductase, or xanthine-xanthine oxidase system, the migration distance of superoxide is not great $(<320 \mathrm{~mm}) .^{23}$ Moreover, generated superoxide is dismuted to $\mathrm{H}_{2} \mathrm{O}_{2}$ by catalase or by pancreatectomised glutathione, or both.

Hydroxyl radical is also generated by HarberWeiss reaction or Fenton type reaction. ${ }^{24}$ Hydroxyl radical is the most potent oxidising and reducing species among free radicals; it immediately attacks other molecules (lipids, glucose, proteins, nucleic acids) around it with a maximum velocity of reaction. ${ }^{16}$ Therefore, superoxide needs to be dismuted at near the generating part. One of the generating sources of oxygen radicals is activated neutrophils which may be suppressed extracellularly by polyethylene glycol-superoxide dismutase (described by Wisner et $a l$ ). Since CV 3611 has a long half life in the circulation and an ability to penetrate the cell, it may suppress oxygen radicals both intracellularly and extracellularly. Our study of a potentially fatal form of experimental pancreatitis showed the protective effects of CV 3611. We do not know whether protection was effected within pancreatic acinar cells, from the interstitium, or in both ways. However, the experiments provide further strong evidence that oxygen free radicals play a pivotal role in experimental pancreatitis.

1 Sanfey H, Bulkley GB, Cameron JL. The pathogenesis of acute pancreatitis. The source and role of oxygen-derived free radicals in three different experimental models. Ann Surg 1985; 201: 633-9.

2 Guice KS, Miller DE, Oldham KT, Townsend CM, Thompson JC. Superoxide dismutase and catalase: A possible role son JC. Superoxide dismutase and catalase: A possible
in established pancreatitis. Am $\mathcal{F}$ S $u r g$ 1986; 151: 163-9.

3 Fridovich I. The biology of oxygen radicals. Science 1978; 201: 875-80.

4 McCord JM. Oxygen-derived free radicals in post ischemic tissue injury. $N E n g l \mathcal{F} M e d$ 1985; 312: 159-64.

5 Nonaka A, Manabe T, Tamura K. Changes of xanthine oxidase, lipid peroxide, and superoide dismutase in mouse acute pancreatitis. Digestion 1989; 43: 41-6.

6 Rutledge PL, Saluja AK, Powers RE, Steer ML. Role of oxygen-derived free radicals in diet-induced hemorrhagic pancreatitis in mice. Gastroenterology 1987; 93: 41-7.

7 Kato K, Terao S, Shimamoto N, Hirata $M$. Studies on scavengers of active oxygen species. I. Synthesis and biological activity of $2-0$-alkylascorbic acids. $\mathcal{F}$ Med Chem 1988; 31: 793-8.

8 Terao S. A novel active oxygen species scavenger, CV 3611. The fourth biennial general meeting of the society for free radical research, Kyoto, Japan 1988: 36

9 Kuzuya K, Hoshida S, Nishida M, et al. Role of free radicals and neutrophils in canine myocardial reperfusion injury: myocardial salvage by a novel free radical scavenger, 2-octadecylascorbic acid. Cardiovas Res 1989; 23: 323-330.

10 Lombardi B, Estes LW, Longnecker DS. Acute hemorrhagic pancreatitis (massive necrosis) with fat necrosis induced in mice by DL-ethionine fed with a choline deficient diet. Am F Pathol 1975; 79: 465-75.

11 Teshima S, Mitsuhida N, Ando M. Determination of $\alpha$-amylase in biological fluids using a new substrate ( $\beta-2$ $\alpha$-amylase in biological fluids using a new substrate ( $\beta-2-$ 1985; 150: 115-24.

12 Kurooka S, Okamoto S, Hashimoto $M$. A novel and simple colorimetric assay for human serum lipase. $\mathcal{F}$ Biochem 1977 81: 361-9.

13 Murata A, Ogawa M, Fujimoto K, Kitahara T, Matsuda Y, Kosaki G. Radioimmunoassay of human pancreatic elastase 1. Enzyme 1983; 30: 29-37.

14 Feinberg SE. The analysis of cross-classified data. Cambridge MA: MIT Press; 1977.

15 Parks DA, Bulkley GB, Granger DN. Role of oxygen derived free radicals in digestive tract diseases. Surgery 1983; 94: 415-22.

16 Freeman BA, Crapo JD. Biology of diseases: Free radicals and tissue injury. Lab Invest 1982; 47: 412-26.

17 Wong C, Flynn J, Demling RH. Role of oxygen radicals in Wong C, Flynn J, Demling RH. Role of oxygen radicals in

18 Braganza MJ. Free radicals. In: Evans CR, Dormandy T, eds. Chemistry, pathology and medicine. London: Richelieu Press, 1988; 357-81.

19 del Maestro RF. Free radical injury during inflammation. In Armstrong D, Sohal RS, Butler RG, Slater TF, eds. Free radicals in molecular biology, aging and disease. New York: Raven Press, 1984; 87-102.

20 Weissman DG. Advances in inflammation research. New York: Raven Press, 1983.

21 Rinderknecht H. Fatal pancreatitis; a consequence of excessive leucocyte stimulation? Int 7 Pancreatol 1988; 3: 105-12.

22 Wisner J, Green D, Ferrell L, Renner I. Evidence for a role of oxygen derived free radicals in the pathogenesis of caerulein

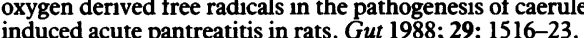

23 Barry H, John MCG. Oxygen toxicity, oxygen radicals, Barry H, John MCG. Oxygen toxicity, oxygen radica

24 Boag JW. Oxygen diffusion and oxygen depletion problems in radiobiology. Curr Topics Rad Res Quart 1969; 5: 141-95. 